
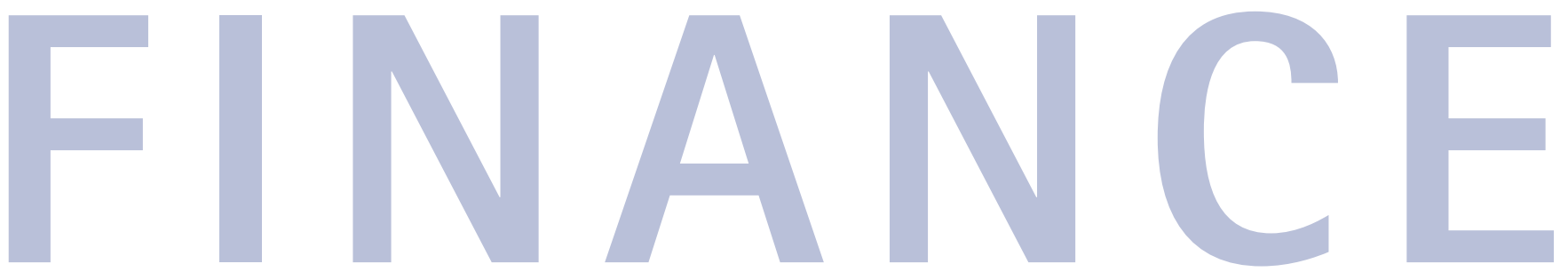

\title{
Wealth matters
}

Wealth Matters is a new independent financial adviser service. They are a brand new company that claims they can help dentists to look after various aspects of their day-to-day lives.

Wealth Matters claims the people behind them are comprehensively trained, and are totally independent. Wealth Matters offer advice for both businesses and for individuals on protection, savings, investments and pensions.

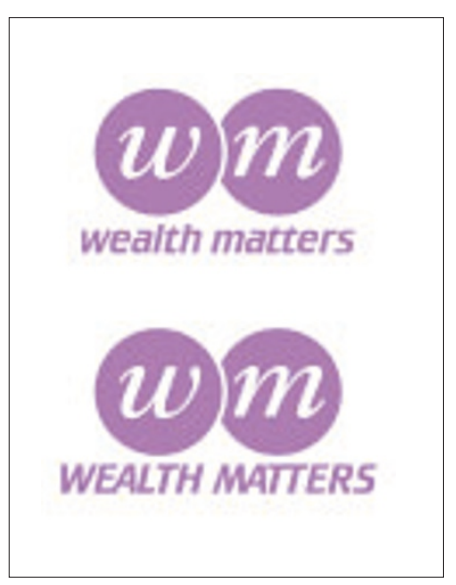

Wealth Matters specialise in helping those with small businesses and the selfemployed and they also claim to have helped companies with their pension schemes. For more information phone 0870 $7708105 . \quad$ Reader response number 56

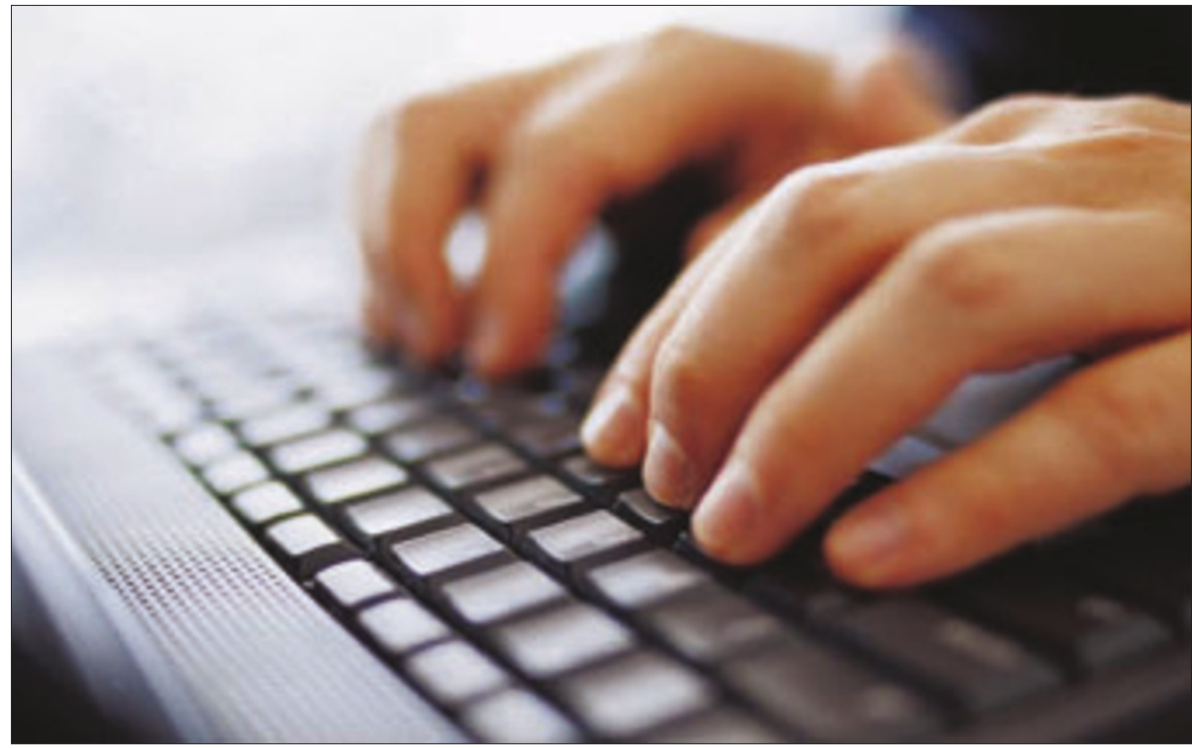

\section{Help your patients spread the cost of surgery}

Frank Taylor Associates (FTA) says a large number of dental patients face the common problem of how they can afford the treatments they need. FTA claims this can now become a distant memory with 3Dee treatment funding.

FTA claims 3Dee treatment funding is simple to administer and available to all patients on all treatments costing from $£ 250$ to as much as £15,000. Payments can be spread over any agreed period up to five years.

FTA also says that arranging the credit agreement is quick and uncomplicated. After agreeing the treatment and cost with their dentist, the patient fills out a one-page credit application form.

Details can either be telephoned or sent online to the credit company and approval in most cases is immediate, allowing treatment to commence with no delay.

For details on how to introduce 3Dee treatment funding in your surgery call 01707653 260 or email chris@ft-associates.com.
Reader response number 55

\section{Are you struggling to cope with the business side of things?}

Some dentists can find that while they enjoy dentistry itself, they continually struggle with the business side of dentistry. Samera claims dentists find it a real chore to run their business effectively, profitably and happily. While they might have attended various business courses, they have found running a practice is still a struggle.

To help dentists Samera trains and educates dentists on the key skills needed to run a successful business. Through one-on-one consulting or group seminars Samera claims they can educate dentists in the key skills of running a successful business.

The courses range from vision planning, finance, marketing and team communication. Samera also claim it is about turning the average dentist into the "business skilled dentist".

For further information contact Samera on 02077244400 or visit their website at www.samera.co.uk.

Reader response number 57

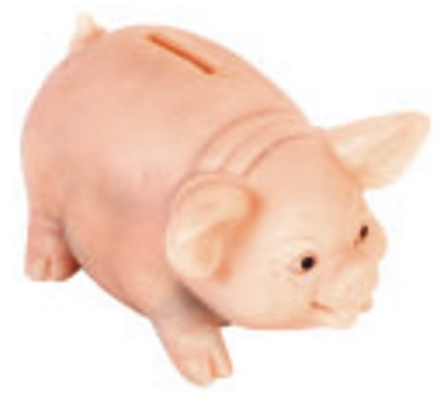

BRITISH DENTAL JOURNAL VOLUME 194. NO. 7 April 122003 


\section{Make the most of the mortgage market}

Steve Jones of Towry Law Mortgage Services reports on how making the most of the UK mortgage market could provide a welcome relief for many dentists.

Towry Law Mortgage Services claims the Government's urge to regulate healthcare professionals could prove to be a costly business for many UK dentists. With the General Dental Council proposed regulations coming into effect in 2004, there is one question on many dentists lips "What's the cost to my business?"

According to Towry Law Mortgage Services one potential drain on practice cashflow is the financial assistance required by dental nurses to obtain their National Certificate or NVQ, one that many of their clients are already starting to feel the effects of. So now more than ever, TMLS claim it is important to look at saving money on existing business and personal commitments to protect the profitability of a dentists practice and secure their own future wealth.

For more information phone 08708985000.

Reader response number 58

\section{Get your credit history back on track}

York based Acorn Commercial Finance, one of the largest independent finance brokers in the UK, has introduced a new service to offer a lifeline for those with adverse credit or defaults in their credit history.

The new service allows clients with adverse or difficult credit history to apply for a commercial loan, at almost standard interest rates. Acorn claims that whereas the majority of lenders in this market will offer an interest rate of 18-36\%, they are now able to offer a dramatic saving at a start rate of only $3.75 \%$ above base rate.

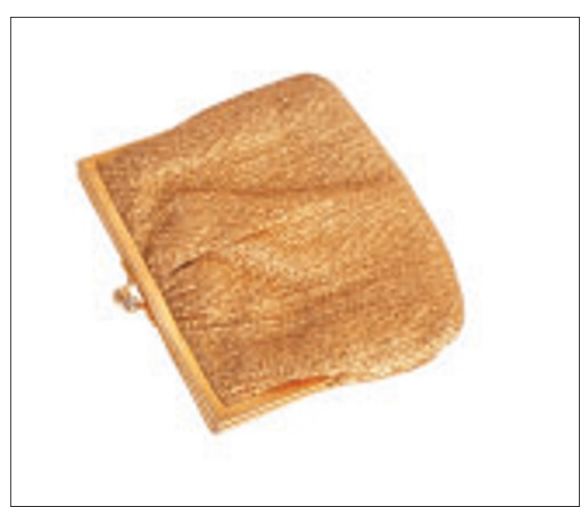

Acorn claims the amount clients can sensibly borrow is therefore greatly increased due to the low rate and it also opens up credit services to all business sectors, from private dentist practices and pharmacies to farms and factories. The new service also carries a direct benefit to accountants and solicitors whose clients have had problems obtaining finance from high street banks.

For more information phone 01943609665 or visit www.acorn-commercialfinance.co.uk.

Reader response number 59

\section{Get help with your investments}

Money4Dentists claims that at the best of times investment decisions can be confusing, and when faced with unfavourable stock market conditions and low interest rates, deciding where to save or invest is more difficult than ever.

The major factors governing any investment or savings decision are how much you have to save and what level of risk you are prepared to accept. Investment today is not just a choice between cash and shares, there are many other options to be considered.

Money4Dentists are one of the leading specialist financial planners for dentists with access to a broad range of financial products. With Money4Dentists recent investment in their own in technology, they are able to comprehensively and continuously monitor the financial products available and offer their clients advice according to their specific needs.

Money4Dentists claims financial planning is very much a two way process between the dentists, their client, and the dentists financial planner. Money4Dentists' focus is to work closely with dentists to develop their own individual financial programme. For more information call 08453455060 or visit www.money4dentists.com.

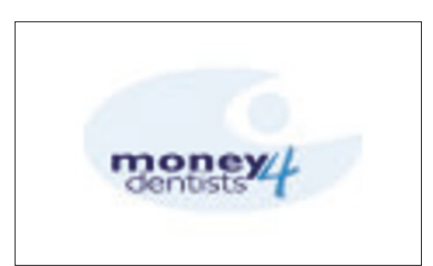

